American Journal of Pharmaceutical Education 2020; 84 (3) Article 7497.

\title{
BRIEF
}

\section{Comparing Empathy Levels in Doctor of Pharmacy Students and Exemplary Pharmacist Preceptors}

\author{
Charlene R. Williams, PharmD, ${ }^{a}$ Philip T. Rodgers, PharmD, ${ }^{b}$ Jacqueline E. McLaughlin, PhD, MS, \\ Thomas A. Angelo, EdD, ${ }^{\mathrm{b}}$ Greene Shepherd, PharmD ${ }^{\mathrm{a}}$ \\ ${ }^{a}$ University of North Carolina, UNC Eshelman School of Pharmacy, Asheville, North Carolina \\ ${ }^{\mathrm{b}}$ University of North Carolina, UNC Eshelman School of Pharmacy, Chapel Hill, North Carolina \\ Submitted December 21, 2018; accepted August 4, 2019; published March 2020.
}

\begin{abstract}
Objective. To determine how student pharmacists' empathy compares to that of exemplary pharmacist preceptors.

Methods. First- through third-year Doctor of Pharmacy students and nominated preceptors demonstrating a model level of empathy in patient care were invited to take the Jefferson Scale of Empathy (JSE) and answer demographic questions. A comparison of total JSE scores was made between students and preceptors. Comparisons of total JSE scores were performed between male and female students, students with and without direct patient care experience, students with and without chronic care experience, and among students based on class year. A factor analysis was completed.

Results. The response rate for students and preceptors was $70.3 \%(n=318)$ and $73.7 \%(n=14)$, respectively. No significant differences in median JSE scores were identified for any of the comparisons. Factor analysis revealed two factors as underlying constructs: "compassionate care" and "perspective taking." Seven of 20 items on the JSE had mean scores $>6.0$ (possible range 1-7).

Conclusion. The majority of students had moderately high cognitive empathy not related to class year that was similar to that of exemplary pharmacist preceptors. A possible ceiling effect was found in several items on the JSE, potentially limiting its use for measuring changes in empathy longitudinally in students with baseline high empathy.
\end{abstract}

Keywords: empathy, pharmacy, preceptor

\section{INTRODUCTION}

The provision of patient-centered care, where patients are active participants in healthcare decisions, requires providers to be able to demonstrate empathy. ${ }^{1}$ Empathy has been associated with a variety of positive clinical outcomes as well as better adherence, improved patient satisfaction, and reduced risk of malpractice litigation. $^{2-8}$ Conversely, low empathy has been linked to provider burnout and could impact provider objectivity. ${ }^{9,10}$ With a wealth of literature underscoring the importance of provider empathy in healthcare, there has been a growing emphasis on empathy training and methods to successfully assess it. Yet literature is sparse on the empathetic communication skills of pharmacists. ${ }^{11,12}$ A study of communication skills in pharmacists in the United Kingdom suggested a need for improved skills in listening and

Corresponding Author: Charlene Williams, UNC Eshelman School of Pharmacy, University of North Carolina, One University Heights CB\# 2125, Asheville, NC 28804. Tel: 828250-3906. E-mail: charlene_williams@unc.edu demonstrating empathy. ${ }^{13}$ In alignment with current trends in healthcare, the Accreditation Council for Pharmacy Education (ACPE) emphasizes patient-centered care in its competencies for Doctor of Pharmacy (PharmD) graduates, and empathy is included as a communication objective in the 2013 Center for the Advancement of Pharmacy Education (CAPE) Outcomes. ${ }^{14,15}$

Various scales to measure empathy in the general population exist, and a widely used instrument specifically in the health professions is the Jefferson Scale of Empathy (JSE). ${ }^{16}$ The JSE, a self-reported measure of empathy, was originally developed through a literature review and Delphi process with medical students, medical residents, and practicing physicians to measure attitudes of medical students towards physician empathy in patient care situations. ${ }^{17,18}$ It has since been adapted and validated for use with other health professions students including pharmacy students. ${ }^{19}$ The original scale was developed using a primarily cognitive definition of empathy. ${ }^{17} \mathrm{Cog}$ nitive empathy involves mental and cognitive functions and is the capacity to interpret and understand another's 


\section{American Journal of Pharmaceutical Education 2020; 84 (3) Article 7497.}

feelings and point of view. ${ }^{19-24}$ Empathy, in the settings of medical education and patient care, is primarily described in the literature as a cognitive attribute ${ }^{23,24}$ and is adaptable through training. ${ }^{25}$ As such, the JSE has been used to assess the effect of educational interventions on cognitive empathy in pharmacy. ${ }^{26-30}$ In contrast to cognitive empathy, affective empathy is a relatively fixed inherent trait that involves experiencing and feeling another's pain or distress. ${ }^{24}$ Excess affective empathy could negatively affect patient outcomes and lead to compassion fatigue and burnout, whereas excess cognitive empathy is not deleterious and is linked to the aforementioned benefits of empathy. ${ }^{24}$ Prior factor analyses of the JSE to determine the underlying constructs of the scale have yielded a twofactor structure in one cohort of pharmacy students ("perspective taking" and "compassionate care") $)^{19}$ and a threefactor structure in medical students ("perspective taking," "compassionate care," and "walking in patient's shoes"). ${ }^{24}$ These factors, named by JSE researchers based on content of JSE items with high-factor coefficients, have been pre-

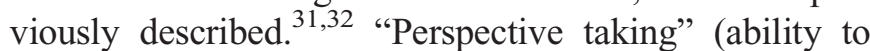
understand another's perspective) is considered the principal component of cognitive empathy. ${ }^{20,31}$ Compassion has been described as an area of overlap between empathy and sympathy that may create a prosocial motivation to help, and "walking in patient's shoes" is putting oneself in the patient's place and thinking like a patient. ${ }^{31-33}$

The JSE consists of a total possible score range of 20140 , with higher scores indicating a more empathic orientation to patient care. ${ }^{17}$ Jefferson Scale of Empathy scores are often reported as $25 \%, 50 \%$, and $75 \%$ percentiles. For example, Fjortoft and colleagues reported 25\%, $50 \%$, and $75 \%$ percentile scores on the JSE as 104,111 , and 119 , respectively, in student pharmacists at one US college of pharmacy. ${ }^{19}$ Cronbach alpha scores of $0.70 \mathrm{~s}$ to $0.80 \mathrm{~s}$ have been reported for JSE studies. ${ }^{24}$ There is evidence of the validity of using the JSE in studies to assess empathy in medical students, physicians, nurse practitioners, nurses, pharmacy students, and dental students. ${ }^{10,17-19,34-36} \mathrm{Na}-$ tional normative data for comparative purposes or evaluating individual scores for pharmacy students are not available to date. This data became available for new osteopathic medical student matriculants in $2018 .{ }^{37}$

It has yet to be determined if there is a standard level of empathy that student pharmacists should strive to attain, and data are relatively lacking regarding whether there are meaningful measurable differences, on average, between empathy levels displayed by student and practicing pharmacists. It is also not known whether a ceiling effect, or score limitation at the top of the scale, exists for the JSE in student pharmacist populations as has been found on several items of the JSE in a cohort of medical students. ${ }^{24}$ If such a ceiling exists for pharmacy students, it could potentially limit use of the scale for accurately measuring change in empathy scores longitudinally. ${ }^{38} \mathrm{~A}$ ceiling effect could also potentially limit the scale's utility for comparing pharmacy students with practicing pharmacists. This study seeks to address those questions by describing cognitive empathy in a cohort of student pharmacists using the JSE as compared to exemplary pharmacist preceptors who are perceived by clinical faculty members as demonstrating a high level of empathy in patient care. Secondary objectives were to confirm the underlying constructs of the scale and to determine whether there is a celling effect of the JSE in a student pharmacist cohort.

\section{METHODS}

The Jefferson Scale of Empathy was administered to student pharmacists and exemplary pharmacist preceptors to compare empathy across students in years one through three of training and with role model pharmacists. The study was reviewed by the university's Institutional Review Board and deemed exempt.

One hundred forty-one first-year (P1) PharmD students, 151 second-year (P2) students, and 160 third-year (P3) students enrolled at the UNC Eshelman School of Pharmacy were invited to anonymously take the Jefferson Scale of Empathy for Health Professions Students (JSEHPS) at the end of a class in the fall semester of 2016. At the time of the study, formal empathy coursework had not yet been implemented into the curriculum. The P1 students had not yet completed any introductory pharmacy practice experiences (IPPEs), and the P2 students had only participated in one IPPE. In the fall prior to taking the JSE, the P3 students had completed two IPPEs and had participated in an empathy assignment that required them to follow a story and participate in a reflection exercise. The JSE-HPS is a 20-question instrument that measures empathy using a seven-point Likert scale. ${ }^{17}$ Ten items on the scale require reverse scoring.

Demographic questions included students' gender, age, experience as a primary caregiver of someone with chronic illness, and prior direct patient care work experience. Prior direct patient care work experience was defined as employment in an environment in which patients received medical care or medications (including pharmacies) and in which students had direct communication with patients related to this care on a regular basis. This did not include any direct patient care provided during pharmacy practice experiences. The questionnaire was anonymous, but students were asked to create a four-digit code with letters and numbers to remember for possible future testing. 


\section{American Journal of Pharmaceutical Education 2020; 84 (3) Article 7497.}

Thirty-nine faculty members and preceptors in the Division of Practice Advancement and Clinical Education at UNC Eshelman School of Pharmacy were asked via email to nominate pharmacist preceptors who had been practicing five to 10 years (beyond novice level in practice) and who demonstrated a high level of empathy in patient care. These faculty members, many of whom were preceptors across the state, were familiar with our highest performing preceptors and thus were asked to assist with this convenience sample. They were provided with Hojat's definition of cognitive empathy, which was used in the development of the Jefferson Scale, to consider as they identified preceptors to nominate: "an uncritical understanding of the patient's experiences, emotions, and feelings. $" 17$ Nominated preceptors were to serve as the exemplary pharmacist preceptors cohort. Nominated preceptors were cross-checked with student evaluations. Nominated preceptors with poor evaluations (ie, scores less than 3 on a 5-point scale ranging from $1=$ not prepared to $5=$ completely prepared) for demonstrating care and compassion as rated by students were excluded as the researchers believed that those who had received higher evaluations would better represent exemplary pharmacist preceptors. The remaining nominated preceptors were invited via email to complete the Jefferson Scale of Empathy for Health Professions (JSEHP), which is similar to the JSE-HPS but with slight modifications in the wording of the questions to be applicable for health professionals rather than students. (For simplicity, the JSE-HPS and the JSE-HP are referred to hereafter as simply JSE.) Demographic questions regarding the pharmacists' age, gender, practice setting, and experience as a primary caregiver of someone with chronic illness were also asked.

All survey results were examined using descriptive statistics. Descriptive results are reported as the mean and standard deviation (SD) or median (range). Exploratory factor analysis using principal axis with promax rotation and Kaiser rule (ie, eigenvalues $>1.0$ ) was used to determine the dimensionality of the student data. This was done to examine construct validity of the JSE data in the sample by determining the extent to which the data in the study reflected the latent variable structure of the original JSE, which proports to measure "perspective taking," "compassionate care," and "walking in patient's shoes." Cronbach alpha assessed factor reliability, which represents the extent to which the survey items within each factor pertained to the factor. ${ }^{39}$

Because of the small number of preceptors included in the data $(n=14)$, nonparametric tests were used for all correlation analyses and group comparisons. Median versus mean scores were used for comparisons because of nonparametric tests. The Kruskal-Wallis test was used to compare JSE total scores by curriculum year (ie, P1 vs P2 vs P3), while Mann Whitney U test was used to compare JSE total scores for two groups: students and preceptors; male and female students; students with and without direct patient care experience; and those with and without chronic care experience. The Fisher exact test was used for categorical data as needed in instances in which the contents of the cell in a contingency table had a frequency of less than five. Spearman rank-order correlation coefficient was used to examine the correlation between JSE total scores and age. The level of significance was set at .05 .

\section{RESULTS}

Forty-five P1 students (31.9\%), 115 P2 students (76.2\%), and 158 P3 students (98.8\%) completed the JSE and demographic questions (Table 1). Two students' responses had missing data that could not be imputed; thus, the data that were provided were subsequently removed from all univariate and bivariate analyses. Nineteen preceptors were nominated by faculty members, and none of those preceptors were excluded as none had poor student evaluations for care and compassion. Fifteen preceptors agreed to participate in the study as exemplary pharmacist preceptors. Fourteen (73.7\%) preceptors completed the JSE and demographic questions (Table 2).

There were no significant differences found between median JSE scores of student group by curriculum year or by preceptor practice type. There were no significant differences between students and pharmacist preceptors, between male and female students, between students with direct patient care experience and those without, or between students with chronic illness caregiver experience

Table 1. Descriptive Statistics for Pharmacy Students Who Participated in a Study Comparing Empathy Levels With Those of Exemplary Pharmacist Preceptors

\begin{tabular}{lccc}
\hline Variable & $\begin{array}{c}\text { P1 Students } \\
(\mathbf{n}=\mathbf{4 5}), \boldsymbol{\%}\end{array}$ & $\begin{array}{c}\text { P2 Students } \\
(\mathbf{n}=\mathbf{1 1 5}), \boldsymbol{\%}\end{array}$ & $\begin{array}{c}\text { P3 Students } \\
(\mathbf{n}=\mathbf{1 5 8}) \mathbf{\%}\end{array}$ \\
\hline Response rate & 31.9 & 76.2 & 98.8 \\
$\begin{array}{l}\text { Female } \\
\text { Student age (years) }\end{array}$ & 71.8 & 57.4 & 64.2 \\
$\quad$ & 6.7 & 7 & \\
$\quad 21$ & 86.7 & 86.1 & 82.9 \\
$22-27$ & 6.7 & 5.2 & 10.8 \\
$28-33$ & 0 & 1.7 & 4.4 \\
$\quad 34-39$ & 0 & 0 & 1.3 \\
$\quad \geq 40$ & 48.9 & 82.6 & 86.7 \\
$\begin{array}{l}\text { Direct patient care } \\
\quad \text { experience }\end{array}$ & & & \\
Care giver for & 15.6 & 25.2 & 20.3 \\
$\quad$ chronic disease & & & \\
\hline & & & \\
\hline
\end{tabular}




\section{American Journal of Pharmaceutical Education 2020; 84 (3) Article 7497.}

Table 2. Descriptive Statistics for Exemplary Pharmacist Preceptors Who Participated in a Study Comparing Empathy Levels With Those of Doctor of Pharmacy Students

\begin{tabular}{lc}
\hline Variable & $\begin{array}{c}\text { Exemplary Pharmacist } \\
\text { Preceptors }(\mathbf{n = 1 4}), \mathbf{\%}\end{array}$ \\
\hline Response rate & 73.7 \\
Female & 78.6 \\
Age (years) & \\
$\leq 21$ & 0 \\
$21-30$ & 28.6 \\
$31-40$ & 64.3 \\
$41-50$ & 0 \\
$51-60$ & 7.1 \\
$>60$ & 0 \\
Caregiver for chronic disease & 35.7 \\
Pharmacy practice setting & \\
Ambulatory care & 57.1 \\
Community & 7.1 \\
Health system (acute care) & 35.7 \\
\hline
\end{tabular}

and those without. Correlations between age and total JSE score were weak for preceptors $\left(\mathrm{r}_{\mathrm{s}}=-.18, p=.53\right)$ and for students $\left(\mathrm{r}_{\mathrm{s}}=-.02, p=.70\right)$. Seven of the 20 items of the JSE (all student groups combined) had mean scores $>6.0$ ( $\max$ score is 7). These were JSE items 2, 4, 7, 8, 12, 14, and 20.

To examine the construct validity of the data, a factor analysis of JSE student responses revealed two factors with loads ranging from 0.43 to 0.71 accounting for $93.3 \%$ of the common variance. Specifically, "compassionate care" accounted for $67.9 \%$ of the common variance and "perspective taking" accounted for $25.5 \%$ of the common variance in the data. Three survey items failed to load onto a factor (ie, factor loading $<0.40$ ), suggesting that these items did not perform according to the original JSE model. After these three items were removed, the correlation between the two factors was 0.46 . A correlation of 0.46 suggests that these two factors were moderately but not strongly related, suggesting that "perspective taking" and "compassionate care" were distinct. Cronbach alpha was 0.80 for "compassionate care" and 0.80 for "perspective taking," suggesting that the items included within each factor demonstrated high internal consistency. Removing these items from the remaining analyses did not alter the significance of the findings. Therefore, they were retained to improve interpretability of the results and comparison with other studies using the JSE. Factor analysis of preceptors was not performed because of the small sample of preceptors.

\section{DISCUSSION}

Cognitive empathy, as measured by the JSE, was similar and moderately high among all three class years and the exemplary pharmacist preceptor cohort. Mean JSE scores were similar to mean JSE scores in two other pharmacy student samples: $\mathrm{M}=110.6$ and $\mathrm{SD}=12.1$ reported by Fjortoft and colleagues and $\mathrm{M}=110.4$ and $\mathrm{SD}=0.8$ noted by Tamayo and team. ${ }^{19,21}$

A possible reason why no differences in cognitive empathy were found between the student groups is that, at that time in the curriculum, students had not received any formal empathy training. It is unknown whether any of the exemplary pharmacists had undergone any formal empathy training. Investigations of empathy interventions have generally shown increases in cognitive empathy post-intervention through measurement of the JSE. ${ }^{25,40} \mathrm{In}$ general, these studies have shown that empathy interventions have shown increases in cognitive empathy immediately post-intervention as measured by the JSE. $^{25,28,30}$ However, the long-term impact that interventions have on students' empathy are less clear. Larti and colleagues demonstrated an increase in JSE scores among nursing students one month after they completed a 12-hour empathy training program. ${ }^{41}$ In contrast, Van Winkle and colleagues measured changes in empathy scores in pharmacy and medical students after a 40minute workshop on aging and found that JSE scores increased immediately after the workshop, but declined over time. ${ }^{28}$ Similarly, Lor and colleagues measured JSE

Table 3. Jefferson Scale of Empathy Scores for all Participants in a Study Comparing Empathy Levels Between Pharmacy Students and Preceptors

\begin{tabular}{lcccccc}
\hline Score & $\begin{array}{c}\text { P1 Students } \\
(\mathbf{n}=\mathbf{4 5})\end{array}$ & $\begin{array}{c}\text { P2 Students } \\
(\mathbf{n = 1 1 5})\end{array}$ & $\begin{array}{c}\text { P3 Students } \\
(\mathbf{n = 1 5 8})\end{array}$ & $\begin{array}{c}\text { Male } \\
\text { Students }\end{array}$ & $\begin{array}{c}\text { Female } \\
\text { Students }\end{array}$ & $\begin{array}{c}\text { Exemplary Pharmacist } \\
\text { Preceptors (n=14) }\end{array}$ \\
\hline JSE, mean (SD) & $114.4(10.8)$ & $111.9(9.7)$ & $111.4(12.2)$ & $114(11.4)$ & $112.7(11.2)$ & $116.4(11.8)$ \\
25\% percentile & 108 & 107 & 104.8 & 104 & 106 & 107.3 \\
$50 \%$ percentile & 115 & 113 & 112.5 & 112 & 113 & 119 \\
75\% percentile score & 123 & 118 & 120 & 118 & 121 & 124 \\
Actual score range $^{\mathrm{a}}$ & $81-135$ & $80-133$ & $72-139$ & $85-135$ & $72-139$ & $93-137$ \\
\hline
\end{tabular}

Abbreviations: JSE = Jefferson Scale of Empathy

${ }^{a}$ Median score

${ }^{\mathrm{b}}$ Possible score range of JSE: 20-140 


\section{American Journal of Pharmaceutical Education 2020; 84 (3) Article 7497.}

at baseline, seven days post-intervention, and 90 days post-empathy intervention (three day simulation involving a patient's loss of vital functions) found that initial increases in empathy in student pharmacists at day seven were not sustained at day $90 .{ }^{30}$ These findings suggest that empathy training throughout the curriculum is needed to increase and sustain students' empathy levels given that, without intervention, empathy levels may decline or stay the same longitudinally in health profession students. ${ }^{28,30}$ Additional research is needed to ascertain the impact of longitudinal interventions on cognitive empathy.

No significant differences in empathy were found between student pharmacists and exemplary pharmacist preceptors. There were no other studies found to date that describe the differences in empathy between student pharmacists and pharmacist exemplars. However, the mean JSE scores of pharmacists and student pharmacists in this study appear similar to Higuchi and colleagues' reported mean JSE scores of 373 Japanese pharmacists $(\mathrm{M}=108.7 ; \mathrm{SD}=12.4)$ and 341 Japanese student pharmacists $(\mathrm{M}=112.5 ; \mathrm{SD}=11.4)$, though a statistical analysis comparing the JSE scores of those samples was not reported. ${ }^{42}$ No other studies reporting JSE scores of pharmacists were identified. Mean JSE scores of 704 physicians $(M=120 ; S D=12)$ and 2637 medical students $(\mathrm{M}=114.3 ; \mathrm{SD}=10.4)$ reported by Hojat and colleagues also appear similar. ${ }^{10,43}$ There was also no statistical analysis to determine whether there were any significant differences between scores of physicians and medical students as these were discreet studies. Further research on differences between empathy in health professions students and health professionals with an interprofessional approach is needed. The findings of the present study suggest that there are no appreciable differences in cognitive empathy between student pharmacists and exemplary pharmacist preceptors, and therefore use of pharmacist empathy scores as a target for achievement with empathy interventions may not be meaningful. Because both groups appear to already possess cognitive empathy, perhaps a future focus of curricula and pharmacist continuing development could be on the demonstration of empathetic communication skills.

Seven items had relatively high scores with a possible ceiling effect (scores >6). Similarly, Hojat and colleagues found that seven items on the JSE for medical students had a possible ceiling effect. ${ }^{24}$ These items were not described in that publication. ${ }^{24}$ However, a new analysis of Hojat and colleagues' data found eight JSE items with mean scores $>6$ (items $2,7,11,12,14,16,19$, and 20), with variances attributed to possible differences in rounding or a slight difference in the number of observations of the original data set and the new analysis
(Jennifer DeSantis, MEd, Senior Research Study Analyst, Thomas Jefferson University, email communication, April 23, 2019). Five JSE items in our study with mean scores $>6$ were the same as those found in the aforementioned medical student sample (items 2, 7, 12, 14, 20). These items were in both "perspective taking" and "compassionate care" categories. Deletion of items is not suggested by creators of the JSE because of significant item-total score correlations and the limitations it would impose on comparative research. ${ }^{24}$ More inquiry is needed to determine whether there are ceiling effects in other populations and why certain items may have a potential ceiling effect over others.

Because student cognitive empathy in the current study was moderately high and comparable to that of exemplary pharmacist preceptors and because several items demonstrated possible ceiling effects, it may be more useful to identify students with low cognitive empathy and use the JSE to measure the impact of empathy interventions in those students versus students that already have higher levels of empathy at baseline. More research is needed in this area as published studies to date have evaluated overall population improvement in JSE score or changes in JSE based on gender. ${ }^{26-30,40}$ Alternatively, the use of other empathy assessments could be investigated for longitudinal empathy interventions. The only empathy scale other than the JSE developed specifically for the health professions is the Kiersma-Chen Empathy Scale (KCES), which is based on both cognitive and affective empathy and has been used to document changes in empathy after an empathy intervention. ${ }^{26,44}$ At this time, only the JSE measures solely cognitive empathy in health professionals, the proposed target of empathy interventions in patient care.

National norms for performance measures to identify high and low scores on the JSE have not been developed for pharmacy. Some tentative cutoff scores in medicine have been suggested based on a longitudinal cohort of medical students: 1.5 standard deviations above the mean score for high scores and 1.5 standard deviations below the mean for low scores. ${ }^{43}$ Additional research in more populations was suggested to determine the predictive validity of cutoff scores. Another area of further inquiry is whether higher JSE scores in student pharmacists and pharmacists lead to better patient outcomes. Preliminary data in a group of 29 family physicians demonstrated that physicians scoring within the top third of the JSE were more likely to have patients with better control of blood glucose and LDL levels. ${ }^{45}$

No gender differences were found in the present study, whereas female subjects have generally presented higher empathy scores than male subjects in US studies of 


\section{American Journal of Pharmaceutical Education 2020; 84 (3) Article 7497.}

pharmacy students, medical students, and other health professions students. ${ }^{17,19,46}$ While JSE scores of 704 physicians demonstrated no significant differences in empathy scores between genders, ${ }^{10}$ gender differences were found in 10 of 11 medical student samples over 11 years. ${ }^{43}$ Consistent with the findings of the present study, empathy scores in pharmacy students in the UK were not significantly different based on gender. ${ }^{47}$ Lack of differences in JSE scores that are based on gender may not be relevant given that the JSE measures cognitive empathy and work in the behavioral sciences suggests that sex differences between men and women in the neural systems involved in cognitive empathy may not be as great as those for affective empathy. ${ }^{48-50}$ Additional inquiry is needed to examine gender influences on affective empathy in pharmacy education.

This study's findings of no significant differences in cognitive empathy in student groups who had experiences in direct patient care or caring for a chronic illness are similar to findings in a study by Manolakis and colleagues in which JSE scores of student pharmacists with a personal/family cancer history were not significantly different. ${ }^{51}$ Further, pharmacy students in the United Kingdom with a chronic condition did not have significantly different empathy compared to those who did not. ${ }^{47}$

Two factors, "compassionate care" and "perspective taking," were derived from the exploratory factor analysis in this study, confirming the two-factor structure in pharmacy students' responses reported by Fjortoft and colleagues in which "perspective taking" and "compassionate care" accounted for $31 \%$ and $8 \%$ of the variance in the data, respectively. ${ }^{19}$ These two factors were also found in Australian paramedic students' responses. ${ }^{52} \mathrm{~A}$ third factor was noted in medical students: "walking in patient's shoes." ${ }^{24}$ The findings of the current study add to the support for a two-factor model of the JSE for pharmacy students.

Several limitations of this study should be acknowledged. The first limitation is that this study involved students from a single school of pharmacy and affiliated preceptors. However, the fact that this study yielded JSE scores and factor analyses similar to those found in previously published research support the generalizability of our findings. ${ }^{19,21}$ The second limitation is the small sample of exemplary pharmacist preceptors that was obtained from the nomination process. Further research in larger populations of pharmacists is warranted to verify findings. The $\mathrm{P} 1$ cohort had a lower response rate than the $\mathrm{P} 2$ and $\mathrm{P} 3$ cohorts. The $\mathrm{P} 1$ class period went over time the day the survey was planned, and the invitation was communicated via video conference to a large portion of the class rather than in person, which could have impacted the response rate. The $\mathrm{P} 1$ cohort had a gender distribution similar to that of the entire P1 class, suggesting the cohort was representative of the class. A third limitation of the study is that the admissions process at UNC Eshelman School of Pharmacy, which uses a multiple mini-interview to assess non-cognitive abilities including the empathy of prospective student candidates, may have led to the most empathetic students being admitted to the school. ${ }^{53}$ An additional limitation is that the JSE is is a self-perception measure. A more meaningful measure may be patient perceptions of student pharmacist and pharmacist empathy. However, data suggest that there is correlation between the JSE and patient perceptions of physician empathy. ${ }^{54}$ Lastly, some students may have had empathy coursework outside of their pharmacy degree that was not collected as part of the study.

\section{CONCLUSION}

The majority of students in this sample had moderately high self-reported empathy levels not related to training year that were similar to those of preceptor pharmacist exemplars. Exploratory factor analysis yielded two factors, "perspective taking" and "compassion care," which further confirmed a previously identified two-factor model of empathy for the JSE in student pharmacist populations. There was a possible ceiling effect in several of the responses to items on the JSE, potentially limiting its use in measuring change in empathy levels for all students longitudinally over the entire pharmacy curriculum. Intentional inclusion of empathy in curriculum design is suggested.

\section{ACKNOWLEDGMENTS}

The primary author completed this work while a trainee of the American College of Clinical Pharmacy Research Institute's Mentored Research Investigator Training (MeRIT) program and thanks MeRIT program mentor Vicki Ellingrod, PharmD, BCCP, FCCP from the University of Michigan College of Pharmacy for her guidance and support. The authors also thank Carlos Rafael Melendez Roman, $\mathrm{PhD}$, for assistance with data analysis.

\section{REFERENCES}

1. Epstein RM, Street RL. The values and value of patient-centered care. Ann Fam Med. 2011; 9:100-103.

2. Stansfield RB, Schwartz A, O'Brien CL, Dekhtyar M, Dunham L, Quirk M. Development of a metacognitive effort construct of empathy during clinical training: a longitudinal study of the factor structure of the Jefferson Scale of Empathy. Adv in Health Sci Educ. 2016;21:5-17.

3. Beck RS, Daughtridge R, Sloane PD. Physician-patient communication in the primary care office: a systematic review. J Am Board Fam Pract. 2002;15:25-38. 


\section{American Journal of Pharmaceutical Education 2020; 84 (3) Article 7497.}

4. Squier RW. A model of empathic understanding and adherence to treatment regimens in practitioner-patient relationships. Soc Sci Med. 1990;30(3):325-339.

5. DiMatteo MR, Sherbourne CD, Hays RD, et al. Physicians' characteristics influence patients' adherence to medical treatment: results from the medical outcomes study Health Psychol. 1993; 12(2):93-102.

6. Zachariae R, Pederson CG, Jensen AB, Ehrnrooth E, Rossen PB, von der Maase H. Association of perceived physician communication style with patient satisfaction, distress, cancer-related self-efficacy, and perceived control over the disease. Br J Cancer.

2003;88:658-665.

7. Hickson GB, Clayton W, Githens PB, Sloan FA. Factors that prompted families to file medical malpractice claims following perinatal injuries. JAMA. 1992;267:1359-1363.

8. Beckman HB, Markakis KM, Suchman AL, Frankel RM. The doctor-patient relationship and malpractice. Arch Intern Med. 1994;154:1365-1370.

9. Yugero O, Ramon Marsal J, Equerda M, Vivanco L, SolerGonzalez J. Association between low empathy and high burnout among primary care physicians and nurses in Lleida, Spain. Eur $J$ Gen Pract. 2017;23(1):4-10.

10. Hojat M, Gonnella JS, Nasca TJ, Mangione S, Vergare M, Magee M. Physician empathy: definition, components, measurement, and relationship to gender and specialty. Am J Psychiatry. 2002; 159:1563-1569.

11. Jubraj B, Barnette NL, Grimes L, Varia S, Chater A, Auyeung V. Why we should understand the patient experience: clinical empathy and medicines optimization. Int J Pharm Pract. 2016;24:367-370.

12. Higuchi $Y$, Inagaki M, Koyama $T$, et al. Emotional Intelligence and its effect on pharmacists and pharmacy students with autistic-like traits. Am J Pharm Educ. 2017;81(4):Article 74.

13. Greenhill N, Anderson C, Avery A, Pilnick A. Analysis of pharmacist-patient communication using the Calgary-Cambridge guide. Patient Educ Couns. 2011;83(3):423-431.

14. Accreditation Council for Pharmacy Education. Accreditation Standards and Key Elements for the Professional Program in Pharmacy Leading to the Doctor of Pharmacy Degree ("Standards 2016"). Published February 2015. https://www.acpe-accredit.org/pdf/ Standards2016FINAL.pdf. Accessed July 9, 2019.

15. Medina MS, Plaza CM, Stowe CD, et al. Center for Advancement of Pharmacy Education 2013 educational outcomes. Am J Pharm Educ. 2013;77(8):Article 162.

16. Fields SK, Mahan P, Tillman P, Harris J, Maxwell K, Hojat M. Measuring empathy in healthcare profession students using the Jefferson Scale of Physician Empathy: Health Provider-Student Version. J Interprof Care. 2011;25(4): 287-293. DOI: 10.3109/ 13561820.2011.566648.

17. Hojat M, Mangione S, Nasca TJ, et al. The Jefferson scale of physician empathy: development and preliminary psychometric data. Educ Psychol Meas. 2001;61(2):349-365.

18. Hojat M, Gonnella JS, Mangione S, et al. Empathy in medical students as related to academic performance, clinical competence, and gender. Med Educ. 2002;36(6):522-527.

19. Fjortoft N, Van Winkle LJ, Hojat M. Measuring empathy in pharmacy students. Am J Pharm Educ. 2011;75(6):Article 109. 20. Davis MH. Measuring individual differences in empathy: evidence for a multidimensional approach. J Pers Soc Psychol. 1983;44:113-126.

21. Tamayo CA, Rizkalla MN, Henderson KK. Cognitive, behavioral, and emotional empathy in pharmacy students: targeting programs for curriculum modification. Front Pharmacol. 7:96. doi: 10.3389/fphar.2016.00096.

22. Zaki J, Ochsner K. The neuroscience of empathy: progress, pitfalls, and promise. Nat Neurosci. 2012;15(5):675-680.

23. Halpern J. What is clinical empathy. J Gen Intern Med. 2003;18:670-674.

24. Hojat M, LaNoue M. Exploration and confirmation of the latent variable structure of the Jefferson scale of empathy. Int J Med Educ. 2014;5:73-81.

25. Hojat M. Ten approaches for enhancing empathy in health and human services cultures. $J$ Health Hum Serv Adm.

2009;31(4):412-450.

26. Chen AM, Kiersma ME, Yehle K, Plake KS. Impact of an aging simulation game on pharmacy students' empathy for older adults. $\mathrm{Am}$ $J$ Pharm Educ. 2015;79(5):Article 65.

27. Chen JT, LaLopa J, Dang DK. Impact of a patient empathy modeling on pharmacy students caring for the underserved. $\mathrm{Am} \mathrm{J}$ Pharm Educ. 2008;72(2):Article 40.

28. Van Winkle LJ, Fjortoft N, Hojat M. Impact of a workshop about aging on the empathy scores of pharmacy and medical students. Am J Pharm Educ. 2012;76(1):Article 9.

29. Kerr JL, Stahnke AM, Behnen EM. Assessing empathy and selfefficacy levels of pharmacy students in an elective diabetes management course. Am J Pharm Educ. 2015;79(3):Article 42. 30. Lor KB, Truong JT, Ip EJ, Barnett MJ. A randomized prospective study on outcomes of an empathy intervention among second-year student pharmacists. Am J Pharm Educ. 2015;79(2):Article 18. 31. Hojat M. Empathy in Patient Care: Antecedents, Development, Measurement, and Outcomes. New York, NY: Springer; 2007:100. 32. Hojat M. Empathy in Patient Care: Antecedents, Development, Measurement, and Outcomes. New York, NY: Springer; 2007:11. 33. Lown BA. A social neuroscience-informed model for teaching and practicing compassion in health care. Med Educ. 2016:50:332-342.

34. Hojat M, Fields SK, Gonnella JS. Empathy: an NP/MD comparison. Nurs Pract. 2003;28(4):45-47.

35. Sherman JJ, Cramer A. Measurement of changes in empathy during dental school. $J$ Dent Educ. 2005;69(3):338-345.

36. Fields SK, Hojat M, Gonnella JS, Mangione S, Kane G, Magee M. Comparisons of nurses and physicians on an operational measure of empathy. Eval Health Professions. 2004;27(1):80-94.

37. Hojat M, DeSantis J, Shannon SC, et al. The Jefferson Scale of Empathy: a nationwide study of measurement properties, underlying components, latent variable structure, and national norms in medical students. Adv Health Sci Educ Theory Pract. 2018;23(5):899-920. 38. Wang L, Zhang Z, McArdle JJ, Salthouse TA. Investigating ceiling effects in longitudinal data analysis. Multivariate Behav Res. 2009;43(3):476-496.

39. Cronbach LJ. Coefficient alpha and the internal structure of tests. Psychometrika.1951;16(3):297-334.

40. Collins KL, Zweber A, Irwin AN. Impact of a fictional reading intervention on empathy development in student pharmacists. Curr Pharm Teach Learn. 2017;9(3):498-503.

41. Larti N, Ashouri E, Aarabi A. The effects on an empathy roleplaying program for operating room nursing students in Iran. $J E d u c$ Eval Health Prof. 2018;15:29.

42. Higuchi Y, Inagaki M, Koyama T, et al. Emotional intelligence and its effect on pharmacist and pharmacy students with autistic-like traits. Am J Pharm Educ. 2017; 81(4):Article 74.

43. Hojat M, Gonnella JS. Eleven years of data on the Jefferson Scale of Empathy-Medical Student Version (JSE-S): Proxy Norm Data and Tentative Cutoff Scores. Med Princ Pract. 2015;24:344-350. 


\section{American Journal of Pharmaceutical Education 2020; 84 (3) Article 7497.}

44. Kiersma ME, Chen AMH, Yehle KS, Plake KS. Validation of an empathy scale in pharmacy and nursing students. Am J Pharm Educ. 2013;77(5):Article 94

45. Hojat M, Louis DZ, Markham FW, Wender R, Rabinowuitz C, Gonnella JS. Physicians' empathy and clinical outcomes if diabetic patients. Acad Med. 2011;86(3):359-365.

46. Petrucci C, La Cerra C, Aloisio F, Montanari P, Lancia L. Empathy in health professional students: a comparative cross-section study. Nurs Educ Today. 2016;41:1-5.

47. Hall M, Hanna LA, Hanna A, McDevitt C. Empathy in UK pharmacy students: assessing differences by gender, level in the degree programme, part-time employment and medical status. Pharm Educ. 2015;15(1):214-247.

48. Christove-Moore L, Simpson EA, Coude G, Grigaityte K, Iacoboni M, Ferrari PF. Empathy: gender effects in brain and behavior. Neurosi Biobehav. Rev. 2014;46(4):604-627.

49. Larson EB, Yao X. Clinical empathy as emotional labor in the patient-physician relationship. JAMA. 2005;293(9):1100-1106.
50. Eisenberg N. Empathy and related vicarious emotional responses. New Dir Child Dev. 1989;44:1-7.

51. Manolakis ML, Olin JL, Thornton PL, Dolder CR, Hanrahan C. A module on death and dying to develop empathy in student pharmacists. Am J Pharm Educ. 2010;75(4):Article 71.

52. Williams B, Brown T, Boyle M, Dousek S. Psychometric testing of the Jefferson Scale of Empathy Health Profession Students' version with Australian paramedic students. Nur Health Science. 2013;15:45-50.

53. Cox WC, McLaughlin JE, Singer D, Lewis M, Dinkins MM. Development and assessment of the multiple mini-interview in a school of pharmacy admissions model. Am J Pharm Educ. 2015; 79(4): Article 53.

54. Glaser KM, Markham FW, Adler HM, McManus PR, Hojat M. Relationship between scores on the Jefferson Scale of physician empathy, patient perceptions of physician empathy, and humanistic approaches to patient care: a validity study. Med Sci Monit. 2007;13:CR291-294. 